\title{
Ciência em narrativas publicitárias: estratégias na TV aberta
}

\section{Science in advertising narratives: strategies in free- to-air TV}

Maria Ataide Malcher ${ }^{1}$

Weverton Raiol

Resumo: Neste artigo apresentamos nove estratégias de uso da ciência em anúncios publicitários televisivos. Entendendo a publicidade como uma narrativa articulada ao nosso cotidiano, portanto, uma mediação de processos de comunicação e uma construtora de modelos, desenvolvemos a pesquisa seguindo a proposta de Motta (2013) para análise comunicacional de narrativas. A partir de sete movimentos analíticos, identificamos as seguintes estratégias: (i) os componentes científicos; (ii) os ambientes científicos; (iii) o convite à experimentação; (iv) a relação com a inovação; (v) a ficção e a realidade; (vi) as animações e ilustrações científicas; (vii) os cientistas e especialistas como personagens; (viii) as celebridades como personagens; (ix) os não especialistas como personagens.

Palavras-chave: publicidade; ciência; narrativa; TV aberta

Abstract: In this paper, we present nine strategies of science usage in TV advertisement. Understanding advertising as a narrative articulated to our daily lives, therefore, a mediation of communication processes and a constructor of patterns, we develop the research following the proposal of Motta (2013) for the communicational analysis of the narratives. Based on seven analytical movements, we identified the following strategies: (i) the scientific components; (ii) the scientific environments; (iii) the invitation to experimentation; (iv) the relation with innovation; (v) fiction and reality; (vi) the scientific animations and

l Universidade Federal do Pará. Belém, PA, Brasil. E-mail: ataidemalcher@uol.com.br

2 Universidade Federal do Pará. Belém, PA, Brasil. E-mail: weverton.raiol@gmail.com 
illustrations; (vii) the specialist and scientist characters; (viii) the celebrity characters; (ix) and the non-specialist characters

Keywords: advertising; science; narrative; free-to-air TV 


\section{Introdução}

Nem sempre percebemos o quanto a ciência está presente no cotidiano por meio da publicidade (CASALLAS-TORRES, 2012; PITRELLI; MANZOLI; MONTOLLI, 2006; SIBILIA; JORGE, 2016). Mas, se pararmos para pensar, podemos facilmente recordar de produtos anunciados como os mais recomendados por especialistas, compostos por fórmulas inovadoras e capazes de transformar o dia a dia. Portanto, o acionamento da ciência nas narrativas publicitárias não se trata de uma novidade, mas nos faz pensar em como as promessas anunciadas são "concretizadas", por exemplo, pela presença de personagens especializados ou pela demonstração de reações em nosso organismo.

Em uma análise da grade de programação da TV aberta brasileira como um todo, foi constatado um destaque quantitativo da publicidade em relação às demais categorias televisivas nas quais há presença de referências à ciência (MALCHER et al., 2017)3. A partir de então, nossos esforços se desdobraram em uma nova pesquisa, na qual buscamos compreender como a ciência é utilizada nas narrativas publicitárias televisivas veiculadas, no período de junho a novembro de 2013, nos intervalos comerciais das emissoras Record Belém e TV Liberal, em Belém-PA.

Dentre os resultados, partindo da concepção da publicidade como elemento fortemente articulado ao mercado e ao cotidiano (TOALDO, 2005; GOMES, 2008; PIEDRAS, 2009; TRINDADE, 2012), identificamos nove estratégias de uso da ciência para a construção de narrativas publicitárias. Neste artigo, o nosso foco é apresentar e discutir essas estratégias e, para isso, retomaremos alguns passos configuradores da pesquisa, a fim de esclarecer como ela foi desenvolvida até os seus resultados.

3 O estudo em questão faz parte dos resultados da pesquisa "Representações da Mulher Cientista na TV Brasileira e no Imaginário de Adolescentes", financiada pelo Conselho Nacional de Desenvolvimento Científico e Tecnológico $(\mathrm{CNPq})$ por meio da Chamada MCTI/CNPq/SPM-PR/ $\mathrm{MDA}^{\circ} 32 / 2012$. 


\section{Aproximações à pesquisa em publicidade}

Como ponto de partida, entendemos que a narrativa publicitária tem como principal objetivo a sedução. Para isso, lança mão de estratégias que possam envolver seus interlocutores. Ao encararmos a publicidade como ação mercadológica (GOMES, 2008) que visa constituir processos de comunicação a partir de estratégias que articulem o contexto de sua produção/veiculação, vamos além da sua função econômica: entramos na sua qualidade de produto midiático e cultural que se insere no dia a dia, configurando percepções e práticas dos sujeitos que consegue envolver.

Toaldo (2005), Piedras (2009) e Trindade (2012) enfatizam a importância dessa dimensão mercadológica da publicidade para a sua inserção no cotidiano. Dessa maneira, ao estudar a publicidade, "podemos conhecer a nós mesmos, como quem assiste, na tela, às nossas vidas reproduzidas em fragmentos" (ROCHA, 2006, p. 2).

No estudo de Toaldo (2005), que analisa o contexto brasileiro a partir de anúncios publicitários, temos a publicidade como mediação de valores morais que se articula com outras instâncias que tecem o social. Ao considerar que os valores presentes nas narrativas publicitárias televisivas se relacionam com o cenário do qual fazemos parte, Trindade (2012, p. 177) também enfatiza que "temos aí uma mediação". Sendo assim, a publicidade busca em nosso cotidiano elementos com os quais podemos nos identificar, a fim de que nos reconheçamos e participemos do que é proposto por ela, atribuindo sentidos às práticas decorrentes do que é publicizado. E essa necessidade de ser constituída e constituir o cotidiano tende a construir modelos, em uma relação com o consumo de bens (TOALDO, 2005; PIEDRAS, 2009; TRINDADE, 2012).

Perceber a publicidade como mediação e construtora de modelos privilegia a análise sob a perspectiva da comunicação como um processo, pois, entendemos que a reconfiguração de sentidos e práticas deriva da identificação e da negociação. Logo, a publicidade tanto introduz novidades quanto corrobora o que é latente, ratificando que ela encontra sentido no cotidiano e só faz sentido ao estar inserida nele. Esse vínculo 
nos faz pensar em como a ciência é estratégica para as narrativas publicitárias, pois esse conhecimento não está descolado das nossas práticas e sua presença em nossas vidas se altera com o tempo, mas tem continuidades quando se trata de "iluminar" o mundo. Essa é uma pista de que a ciência possui em nossa sociedade um papel importante, ou não envolveria os consumidores com os produtos anunciados e certamente não seria uma estratégia recorrente para a publicidade.

\section{Procedimentos metodológicos}

A nossa pesquisa, desdobrada de um projeto anterior, inicia com os anúncios já coletados ${ }^{4}$ e, para os objetivos estabelecidos, refinamos esse corpus. Considerando a proposta de que a publicidade é o elemento que não só interrompe, mas, sobretudo, costura a programação (PIEDRAS, 2009; TRINDADE 2012), analisamos 83 anúncios inseridos nos intervalos comerciais ${ }^{5}$, que foram organizados por categorias de produtos $\operatorname{anunciados}^{6}$ (Tabela 1).

Tabela 1 - Anunciantes e anúncios por categorias de produtos

\begin{tabular}{lll}
\hline CATEGORIA DE PRODUTO & ANUNCIANTES & ANÚNCIOS \\
\hline Alimentos & 4 & 7 \\
Bebidas & 1 & 1 \\
Campanhas de utilidade pública & 1 & 1 \\
Combustíveis e derivados & 2 & 4 \\
Cosméticos & 6 & 18 \\
Higiene doméstica & 2 & 2
\end{tabular}

4 Na pesquisa anterior, foram gravadas 648 horas de programação das emissoras Record Belém e TV Liberal, coletadas no período de junho a novembro de 2013. A coleta foi realizada por meio da técnica de semanas construídas, sendo sorteados aleatoriamente duas vezes cada dia da semana (domingos, segundas-feiras etc.) dentro do referido período, até compor duas semanas de programação televisiva.

5 O corpus é composto por peças dos seguintes anunciantes: Acnase; Activia; Avon; Canal Futura; Celpa; Chevrolet; Cicatricure; CNPq; Colgate; Danoninho; Densia; Dove; Fiat; Flanax; Floratil; Ford; Friboi; Goicoechea; Head Shoulder; Imecap Hair; L'Oréal Paris; Listerine; Medicasp; Mr. Músculo; Neutrogena; Top Therm; Pantene; Pepsi; Petrobrás; Pointts; Qiar; Respire Melhor; Shell; Shot-B; Targifor C; Tiguvon; Tio Nacho; TRESemmé; Tylenol; e Veja.

6 Esta organização é uma indicação de Trindade (1999). Contudo, atualizamos a proposta do autor a partir dos segmentos de mercado que investem atualmente em publicidade (KANTAR, 2016). 
Tabela 1 (continuação)

\begin{tabular}{lll}
\hline CATEGORIA DE PRODUTO & ANUNCIANTES & ANÚNCIOS \\
\hline Higiene pessoal & 9 & 24 \\
\hline Medicamentos & 7 & 8 \\
Medicamentos veterinários & 1 & 1 \\
Outros produtos farmacêuticos & 4 & 6 \\
Serviços & 2 & 3 \\
Tônicos fortificantes e vitaminas & 3 & 3 \\
Veículos e acessórios & 3 & 5 \\
TOTAL & $40^{*}$ & 83 \\
\hline
\end{tabular}

Fonte: Dados da pesquisa.

Nota: *Os anunciantes podem constar em mais de uma categoria de produto. Porém, no total, esses anunciantes são contabilizados apenas uma vez.

Entendemos que a análise das narrativas publicitárias televisivas a partir da noção de publicidade como mediadora e construtora de modelos é consonante com a preocupação de Motta (2013) de investigar a narração sob o olhar comunicacional, buscando entender como as estratégias narrativas se revelam como tentativas de estabelecer diálogos entre as produções massivas e seus interlocutores.

Dessa maneira, levamos em conta que as narrativas são produções culturais inseridas em contextos e criadoras de significações sociais, imbricadas nas dimensões socioculturais e comunicacionais. Essa noção nos ajuda a considerar a narrativa como a cultura em ação, e aí estudamos a criação de estratégias que geram significados sobre a realidade. Para fins analíticos, Motta (2013) nos orienta a pensar as narrativas em três planos, pois, como processos, elas não são divisíveis. São os planos da expressão, do conteúdo e das metanarrativas 7 . Segundo o autor, a perspectiva da Comunicação deve ter o foco no plano do conteúdo, já que a análise suscitará idas e voltas ao demais planos.

7 Motta (2013) indica alternativas para denominar os mesmos planos. Considerando as revisões bibliográficas e nossa proposta, optamos por nomear os três planos como: da expressão, do conteúdo e das metanarrativas. 
O plano da expressão é a superfície, onde conseguimos identificar o verbal, o sonoro, o visual - são as formas de expressar que nos levam à história, é por elas que adentramos no conteúdo. O plano do conteúdo é a projeção da narrativa a partir dos recursos expressivos - por mais que não exista sem os recursos verbais, sonoros e visuais, ele possui uma gramática própria: as personagens e seus papéis, os cenários, o encadeamento das ações, entre outras questões que envolvem a intriga. No plano das metanarrativas estão as questões que permeiam a nossa cultura. Lá estão o tema de fundo, os imaginários que evocamos para compreensão do que é narrado, nesse plano configuramos a "moral da história” e todas as ações, mesmo as mais fictícias, possuem um elo com o que pode acontecer.

Após o entendimento dos planos, realizamos sete movimentos de análise (MOTTA, 2013), que se dão simultaneamente, mas que são ordenados para que seja possível ter a noção de que podemos nos aprofundar na narrativa em cada um deles: (i) observar e decompor a história; (ii) compreender a articulação entre as partes que a constituem; (iii) deixar surgirem os seus episódios; (iv) perceber o fio que os conduz; (v) analisar os personagens como figura central das ações; (vi) observar as estratégias argumentativas; (vii) entender os conflitos da superfície à profundidade.

Os dois primeiros movimentos resultam, respectivamente, em uma sinopse-resumo e uma linha do tempo que auxiliam nos demais passos. Começamos, portanto, compondo e recompondo as 83 histórias. Geramos as sinopses-resumo e identificamos que, por conta de repetições e combinações, uma seleção de 30 anúncios contemplava os recursos identificados até então. Posteriormente, elaboramos uma proposta de linha do tempo que conjugou a estrutura comum ao roteiro do anúncio (apresentação, argumentação e cumplicidade), a partir de Figueiredo (2014), e a estrutura da narrativa publicitária (situação inicial $\square$ perturbação $\square$ transformação $\square$ resolução $\square$ situação final), indicada por Flausino e Motta (2007).

A partir da adoção dessas estruturas, analisamos os 30 anúncios selecionados a fim de compreender as lógicas de construção das suas 
narrativas. Para Motta (2013, p. 146), é preciso encarar a "narrativa como elo da performance de interlocutores em um processo de comunicação". Dessa maneira, realizamos os cinco movimentos seguintes, simultaneamente, a partir da sinopse-resumo e da linha do tempo de cada anúncio. E nesse processo percebemos as estratégias de uso da ciência que apresentamos a seguir.

\section{Estratégias de acionamento da ciência em narrativas publicitárias televisivas}

Partindo das premissas teórico-metodológicas apresentadas, identificamos nove estratégias narrativas da publicidade televisiva que envolvem a ciência: (i) os componentes científicos; (ii) os ambientes científicos; (iii) o convite à experimentação; (iv) a relação com a inovação; (v) a ficção e a realidade; (vi) as animações e ilustrações científicas; (vii) os cientistas e especialistas como personagens; (viii) as celebridades como personagens; (ix) os não especialistas como personagens. A seguir, apresentaremos como elas se configuram e quais são as categorias de produtos que as utilizam.

\section{Componentes científicos}

O componente científico é o elemento, substância ou nutriente presente na constituição do produto anunciado. Em alguns casos, ele é o fio condutor da argumentação do anúncio, com informações a respeito de suas características e dos resultados que proporciona. Em outros, é apenas mencionado brevemente, tendo como foco o seu resultado. Os componentes são enfatizados ou citados na narrativa publicitária para fazer da ciência um atributo do produto.

Os componentes científicos são, geralmente, encontrados em produtos da categoria higiene pessoal, mas também nas categorias de alimentos, cosméticos, higiene doméstica, medicamentos e tônicos fortificantes e vitaminas. Além da inovação, eles têm a função de dar ao anunciante a característica de efetividade, pois geralmente são produtos com propriedades únicas. Mesmo aqueles componentes que não são 
16483

novos ou são encontrados em outros produtos se constroem a partir do que podem proporcionar de transformador.

No anúncio da linha de produtos capilares Elseve Arginina Resist X3, da L'Oréal Paris (Figura 1), os componentes científicos são utilizados no processo de argumentação, especificamente nos pontos de transformação e resolução da narrativa. Eles se mostram como aquilo que conduz o problema apresentado à solução esperada.

Figura 1 - L'Oréal Paris - Elseve Arginina Resist X3 (30”)
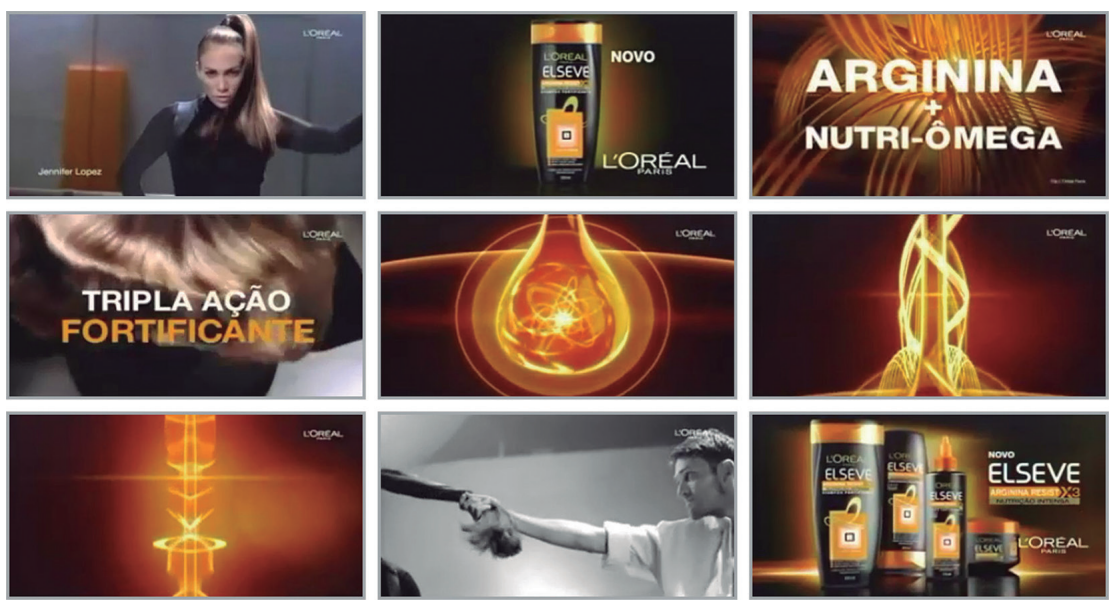

Fonte: Acervo da pesquisa.

A ação do componente científico é apresentada com as animações que iniciam com os anéis de nutri-ômega e arginina em contato com o bulbo capilar, de onde se desprendem fios que percorrem a fibra capilar, ilustrando a "tripla-ação" prometida pelos produtos. Em sua argumentação, o anúncio recorre à noção de resultado efetivo.

Ancorados, principalmente, na presença do que é exclusivo, a locução (explicação) e a animação (demonstração) também são reforços importantes deste argumento. Mas não só isso, a própria presença da cantora Jennifer Lopez, as cores, o nome dado ao resultado ("tripla-ação fortificante") também são recursos tentativos de comunicar a ciência como a diferenciação do produto ao consumidor. 


\section{Ambientes científicos}

Outra estratégia que está presente nos anúncios publicitários é a ciência como fornecedora do contexto de criação ou validação do produto, o que denominamos como ambientes científicos. Diferente dos componentes que constituem, os ambientes criam um espaço de certificação dos produtos, relacionando-os à ciência.

Os ambientes científicos, geralmente, são cenários de laboratórios, consultórios ou escritórios. Mas também consideramos como ambientes científicos os locais em que a narrativa desenvolve esse contexto científico evidente, seja na sala de casa ou cenário de programa de TV. Nesses casos, o ambiente tem seus elementos associados a processos de pesquisa, experimentação, tratamentos, etc. Essa estratégia está presente nas categorias de alimentos, combustiveis e derivados, higiene doméstica, medicamentos, serviços e veículos e acessórios - que, geralmente, apresentam os ambientes com a presença de cientistas ou especialistas, caracteristicamente trajando jalecos brancos.

O anúncio do automóvel S10, fabricado pela Chevrolet (Figura 2), por exemplo, traz o ambiente científico em diferentes momentos da narrativa, até mesmo por conta da sua natureza de contextualização. Essa ocorrência em diferentes etapas do anúncio é uma característica dos anúncios que recorrem a essa estratégia narrativa.

Figura 2 - Chevrolet - S10 (30")
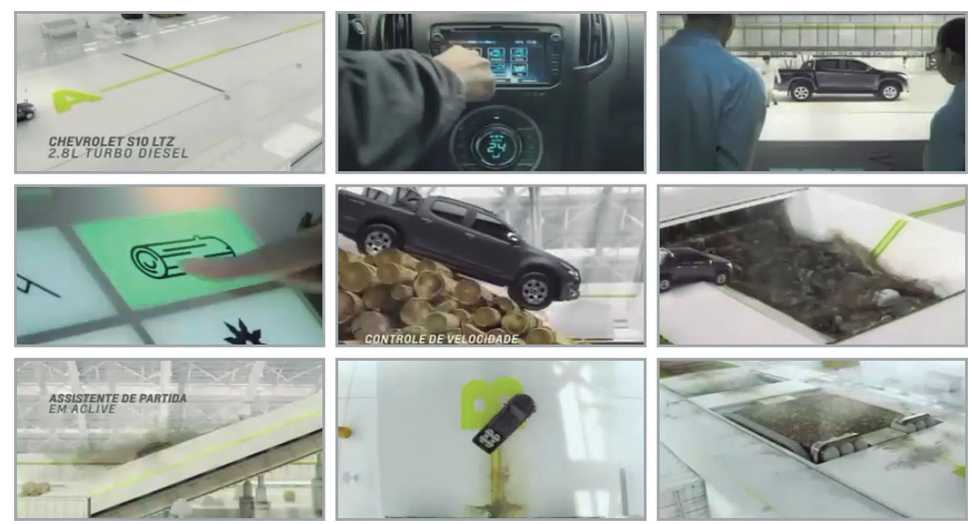

Fonte: Acervo da pesquisa. 
Para divulgar um modelo de automóvel para consumidores que valorizam resistência, mesmo que não haja um componente científico, a ciência está explicitamente presente na criação e de validação do produto. No caso da Chevrolet, tanto certifica que o produto é capaz de enfrentar os obstáculos (rampas, correntezas, etc.), quanto atribui o processo de experimentação como uma qualidade da marca. Ao explicitar esses processos, a ciência se torna uma certificação e reforça o investimento da marca no desenvolvimento dos produtos com acompanhamento de especialistas.

\section{Convite à experimentação}

Tanto os componentes quanto os ambientes científicos apresentam a ciência como elemento fundamental para os resultados desejados. E um passo importante para isso é a experimentação, mas, sobretudo, o convite à validação. Essa comprovação é feita a partir do consumo do que está sendo anunciado. Consideramos como estratégia o convite explícito à certificação da eficiência do produto.

Essa é uma estratégia presente na categoria de alimentos, cosméticos, higiene doméstica, higiene pessoal, medicamentos, e veículos e acessórios. No caso de Activia e Listerine, são propostos desafios de consumo diário, para um bom funcionamento do intestino e limpeza bucal adequada. Já Targifor configura a presença de um apresentador de programa televisivo, mas os testes também são no dia a dia de um consumidor que precisa de mais energia.

Os convites à experimentação também se dão em ambientes laboratoriais, em torno de experimentos e processos de comprovação. É o caso do anúncio do Renew Clinical da Avon: o que conduz a narrativa desde o início é um convite à comprovação da sua ação antirrugas (Figura 3). 
Figura 3 - Avon, Renew Clinical (30")
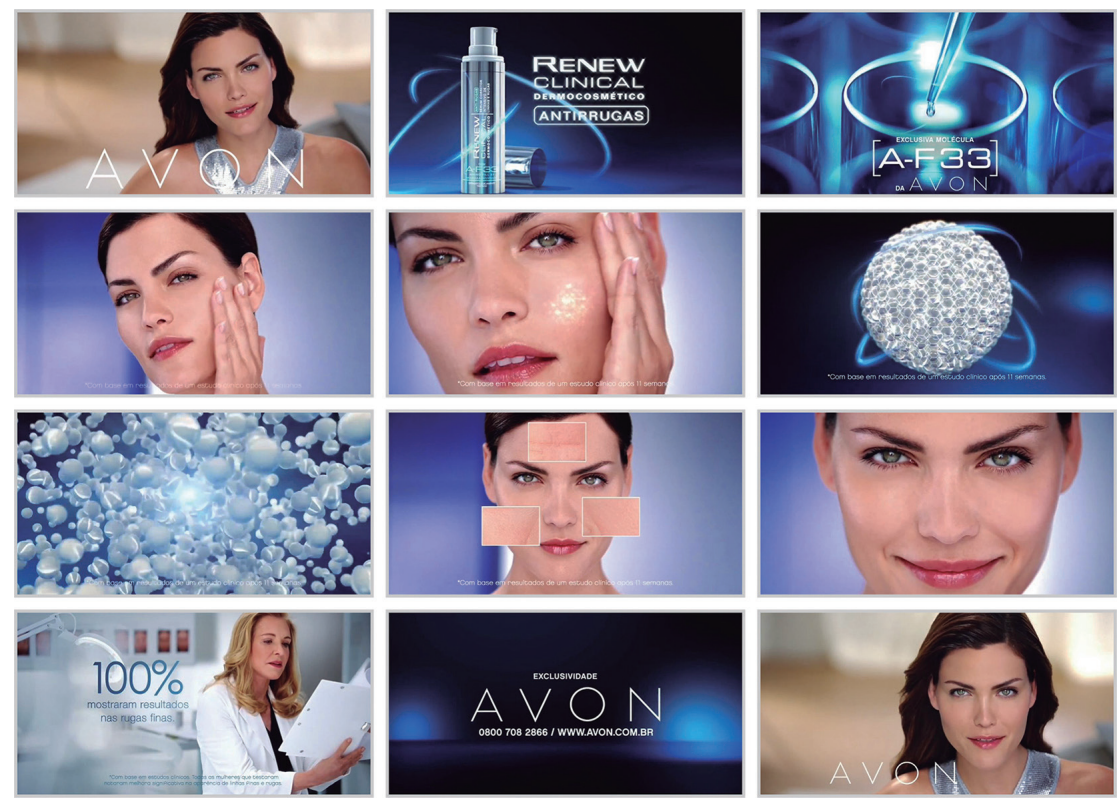

Fonte: Acervo da pesquisa.

Em sua apresentação, o anúncio traz uma personagem que pode ser considerada como um retrato de padrão de beleza ${ }^{8}$. Seu papel é apontar que nem a descoberta da marca, nem sua beleza são milagres; mas, sim, resultados do conhecimento científico que a Avon detém. Essa noção é complementada pela animação que demonstra o efeito do produto ("explosão de colágeno"), enfatizando a molécula como a grande descoberta científica. As informações textuais apontam os resultados clínicos, a locução explica a ação do produto, os enquadramentos privilegiam o rosto e a pele das personagens.

Assim, a tecnologia que propicia beleza reforça a noção experimental, contemplando o componente científico e seus processos de criação e certificação, vistos a partir da manipulação de instrumentos laboratoriais. Esses elementos constroem uma narrativa sobre um resultado

$8{ }^{10}$ Entendemos como padrão de beleza a imagem do corpo idealizada pela sociedade em determinada época. 
mensurável que pode ser conferido com o consumo do produto. A ideia de ciência, nesse caso, solicita nosso testemunho das suas inovações.

\section{Relação com a inovação}

Outra estratégia importante que a narrativa publicitária constrói é a ideia de inovação. Relacionada à ciência, consideramos que inovação traz a noção de exclusividade aos produtos anunciados, pois, como já vimos, os anúncios falam de descobertas, avanços, fórmulas e outras denominações para um desenvolvimento científico representado como útil, criativo, tecnológico e inovador.

A ciência como sinônimo de inovação foi identificada nos anúncios de alimentos, cosméticos, higiene doméstica, higiene pessoal, medicamentos e veículos e acessórios. Em alguns, os produtos utilizam a estratégia de componentes científicos, mas enfatizam neles a exclusividade das marcas. O que não ocorre em produtos que possuem vitaminas, porque essas não podem ser ditas propriedades de uma marca.

Enfatizar o processo de criação e a composição do produto também são formas de acrescentar às narrativas publicitárias a impressão de uma ciência inovadora, corroborando diretamente com o objetivo da publicidade: criar e consolidar diferenciais aos produtos anunciados, buscando mais chances de envolver o consumidor. Sabemos que o novo é uma das características da publicidade (FLAUSINO; MOTTA, 2007), quando relacionado ao conhecimento científico não seria diferente, pois ele é apresentado como elemento essencial à inovação do que consumimos, renovando o xampu, o medicamento e outros produtos que nos ajudam na rotina diária.

A partir do anúncio da Petrobrás em homenagem ao seu engenheiro mecânico Frederico Kremer, trazemos alguns pontos sobre essa estratégia de relação da ciência com a inovação na narrativa publicitária (Figura 4). 
Figura 4 - Petrobrás, "Frederico Kremer, gente é o que inspira a gente" (30")
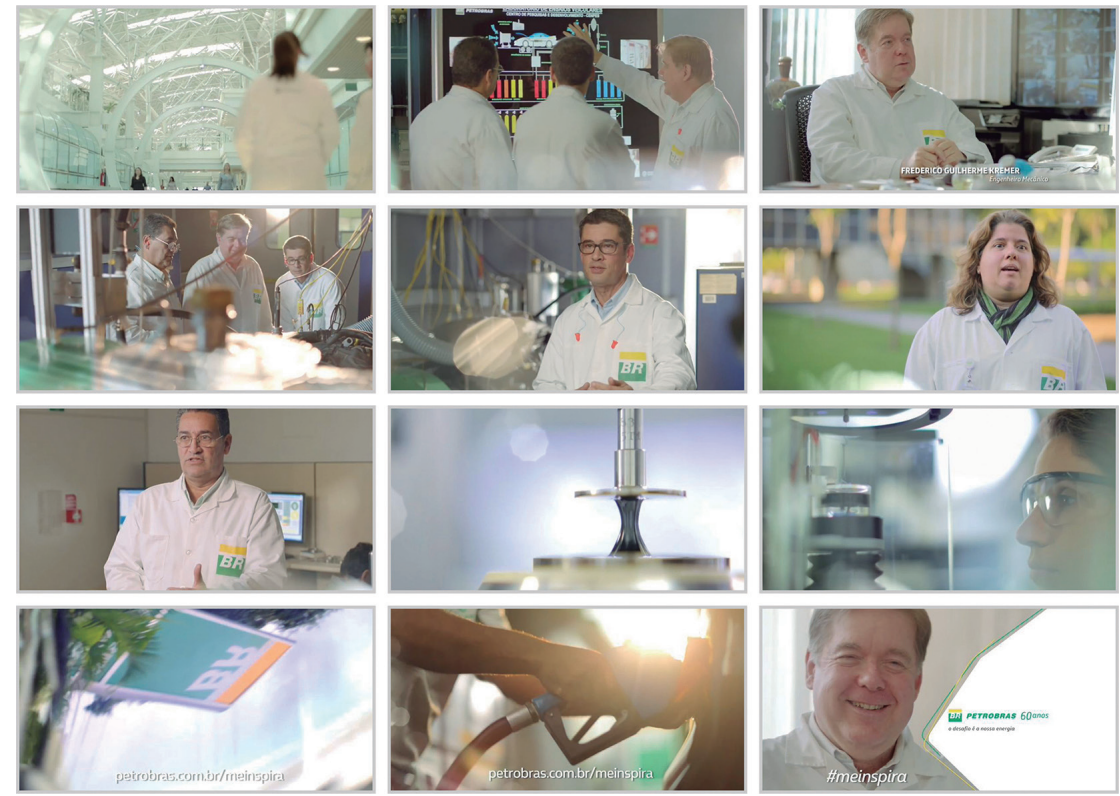

Fonte: Acervo da pesquisa.

Como personagem de destaque na narrativa, Kremer é revelado logo no início do anúncio, associando a carreira que sempre sonhou aos processos de desenvolvimento científico e à inovação. O anúncio segue alternando entre imagens do engenheiro e outras pessoas trabalhando em laboratório. Os sonhos de Kremer se configuram no decorrer da narrativa como coletivos, e os demais personagens enfatizam como ele é uma inspiração, que sente a necessidade de ir sempre além, desenvolver produtos e trazer inovação à sociedade. O senso coletivo construído pelo depoimento do engenheiro representa todos que trabalham com ele e a própria Petrobrás. Logo, contando-nos a sua história, ele afirma que todos estão envolvidos em processos de criação.

Apresentar novidades, na publicidade, é uma das contribuições para aumentar ou manter a circulação de bens de consumo. Em nossa análise, é evidente que a referência à ciência é utilizada como aliada na construção desse argumento. As narrativas publicitárias, nesse sentido, 
se constroem para que percebamos a inovação como uma base das marcas. Mesmo quando o foco são pessoas e histórias, a transformação está contida nos produtos.

\section{Ficção e realidade}

Estar "entre" o real e o fictício é uma característica comum a qualquer narrativa. Quando a referência à ciência é inserida nessa relação, entendemos que esse conhecimento é o responsável por concretizar/ realizar alguns elementos. Logo, essa estratégia é encontrada em todos os anúncios analisados. Em alguns casos, o foco é a realidade, como no anúncio de Tiguvon, que utiliza imagens reais de aplicação e apresenta o organismo bovino em uma animação anatômica. Mesmo nesse caso, a animação não deixa de trazer o lúdico e o didático, uma forma de simular a ação do produto e os resultados obtidos.

Os personagens envolvidas com a ciência podem ser diversos: o cientista, o especialista, a celebridade e o sujeito comum. Podem ser médicos, engenheiros, donas de casa, pais, ou atores que interpretam qualquer um desses papéis. Assim, a publicidade tem licença para trazer os fatos, mesmo que científicos, a partir do fictício. Os cenários podem ser futuristas e animados, mas representam o mundo no qual vivemos e possuem elementos de reconhecimento e idealização do nosso cotidiano.

Identificamos recursos que privilegiam a semelhança com o real e outros que buscam a abstração para ter mais expressividade, como no anúncio "Matemático", da Pespi, no qual é claro o contrato com a narrativa publicitária: real ou fictícia, o importante é ser possível (Figura 5).

O enredo se desloca do que é corriqueiro para uma mãe até acontecimentos praticamente inacreditáveis, mas baseados na realidade: economizar na compra do refrigerante, permite investir na educação do filho e dar a ele a oportunidade de ser um cientista com chances de ganhar um prêmio científico milionário. A proposta da marca é imprimir na narrativa um tom descontraído e caricato, mas verossímil. 
Figura 5 - Pepsi, "Matemático" (30")
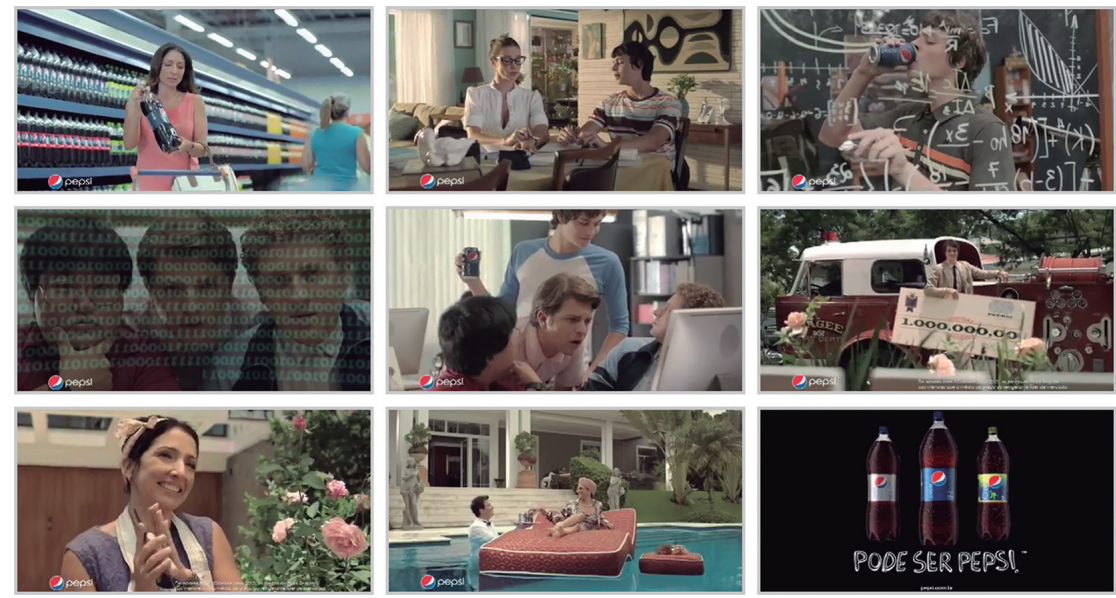

Fonte: Acervo da pesquisa.

Na publicidade, mesmo a ciência reconhecida pelo compromisso com a racionalidade pode ser pensada como maneira de acrescentar ficção à narrativa. No anúncio da Pepsi, não temos o conhecimento científico sendo demonstrado, mas sim a carreira científica como argumento de prosperidade, de investimento que pode trazer retornos financeiros e sociais. A noção de ciência não está presente como processo de criação, nem como componente ou validação do produto. Seu papel é representar uma trajetória de prestígio, de um conhecimento reconhecido pela sociedade. Outro ponto que é importante destacar é a caracterização do personagem, em alguns momentos, como alguém genial e pouco esforçado, acentuando a noção de que a ciência é um "ambiente" ou uma "ação" de pessoas inteligentes, com vocação natural para aprender.

\section{Animações e ilustrações científicas}

Apresentar e demonstrar os processos e resultados de forma didática, lúdica e/ou bem-humorada é outra estratégia que identificamos nos anúncios publicitários analisados. Além de alguns dos anúncios que já apresentamos, outros também trazem as ilustrações e animações como a 
condução dos seus argumentos. Nelas estão a demonstração de ação dos componentes científicos, principalmente no organismo humano, com didaticidade e ludicidade na caracterização de cenários. Essa estratégia ajuda a compreender os pretensos processos de desenvolvimento e reação dos produtos anunciados, pois, quanto melhor pudermos entender, mais chances temos de nos envolver no argumento tecido.

Identificamos essa estratégia nas categorias de alimentos, cosméticos, higiene pessoal, medicamentos, medicamentos veterinários e tônicos fortificantes e vitaminas. E podemos dizer que elas se apresentam em graus diversos entre representações próximas do real e abstrações. No primeiro caso, as narrativas trazem modelos anatômicos com detalhes que nos permitem identificá-los como parte de um corpo humano (exceto Tiguvon, que é aplicado em bovinos). Assim, temos vasos sanguíneos, camadas da pele, músculos, como maneiras de acionar uma dimensão didática.

Há também anunciantes que utilizam animações menos fiéis à anatomia humana, mas que, por meio de recursos como as cores e as formas abstratas, conseguem vincular o resultado do produto anunciado ao nosso organismo. O que percebemos de vantagem na abstração é que ela permite apelos visuais mais expressivos, representando explosões e restaurações, como já vimos nos anúncios da L'Oréal Paris e da Avon.

O papel importante da animação científica pode ser observado no anúncio Uma corda, mil aprendizados, da Danoninho (Figura 6). As animações e ilustrações entram em dois pontos do anúncio. A primeira é logo no início com a função de contextualizar o tema, como uma vinheta, indicando o conteúdo que será anunciado. Já a animação com mais potencial explicativo/demonstrativo tem como função explicitar a absorção da vitamina D e do cálcio no organismo como nutrientes essenciais. O desenho com formas arredondadas e lúdicas é importante para fundamentar como o produto ajuda a ter ossos mais fortes para, por conseguinte, garantir à criança a possibilidade de brincar e aprender.

Percebemos que as animações e ilustrações extrapolam suas características como recursos e se estabelecem como estratégias importantes 
para explicar os elementos do conhecimento científico, de modo que nos aproximemos deles e os reconheçamos em nosso dia a dia, trazendo a ciência para mais perto na construção de nossas práticas.

Figura 6 - Danoninho, "Uma corda, mil aprendizados" (30")
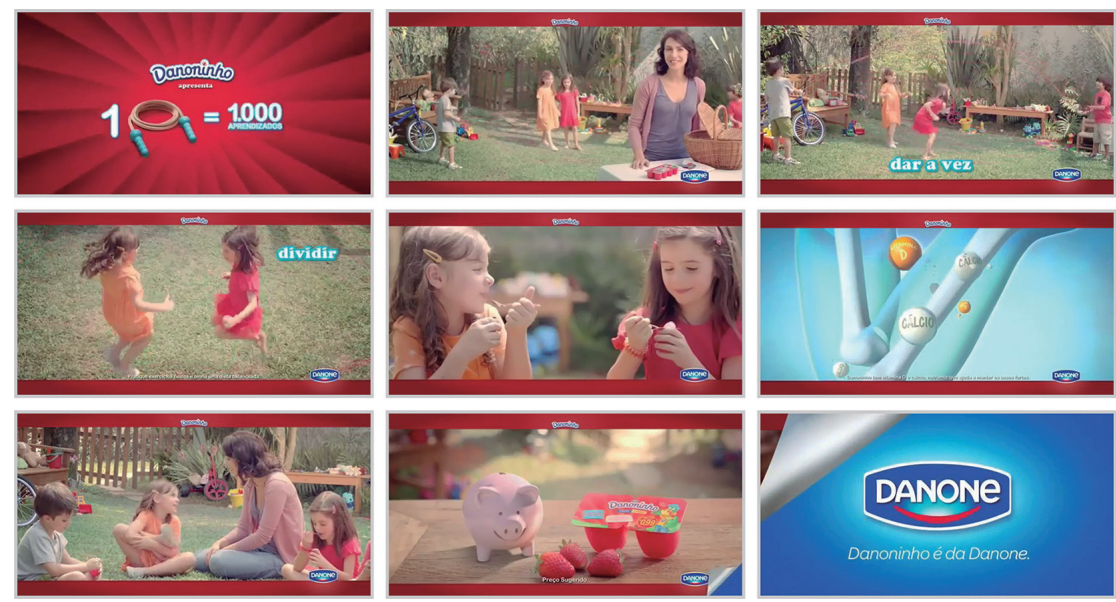

Fonte: Acervo da pesquisa.

\section{Cientistas e especialistas como personagens}

Os cientistas e especialistas podem ser reconhecidos como detentores do conhecimento científico. A partir deles, as narrativas apresentam problemas e suas respectivas soluções. A presença dessas personagens pode ser considerada uma forma direta de propor a ciência como um atributo dos produtos anunciados das categorias de alimentos, combustíveis e derivados, cosméticos, higiene doméstica, medicamentos, outros produtos farmacêuticos, serviços e veículos e acessórios. Nesses anúncios, os cientistas e especialistas consolidam o teor científico das informações ao explicitar o quanto um problema pode ser inconveniente e o quanto pode ser prático solucioná-lo.

Há três formas de apresentação de cientistas e especialistas nas narrativas publicitárias. Na primeira, eles possuem voz e aparecem como personagens que explicam um problema e/ou uma solução que envolve 
o produto. Na segunda, a sua presença é identificada a partir do contexto e/ou dos elementos textuais e sonoros. Já na terceira, suas participações são conferidas apenas por partes do seu corpo, como seus braços com jaleco branco e luvas. Em sua primeira forma, quando a personagem tem uma função explicativa, ele assume um papel central. Porém, em todos os casos, a presença dessas personagens caracteriza um componente ou ambiente como científico, mesmo que elas não sejam o único recurso utilizado.

No anúncio do creme dental Colgate Sensitive Pró-Alívio, o uso do mosaico, a locução em primeira pessoa, além dos efeitos de sons ambientes, como ruídos de espaços públicos, são recursos que reforçam que a narrativa trata da memória da personagem central. A sensibilidade dentária faz com que ela perca os momentos felizes, em família. Mas, como parte da própria memória, ela recorda do seu dentista. É assim que o especialista é mencionado e acionado como quem pode, mesmo sem falar diretamente, nos recomendar a solução de problemas cotidianos (Figura 7).

Figura 7 - Colgate, Sensitive Pró-Alívio (30”)
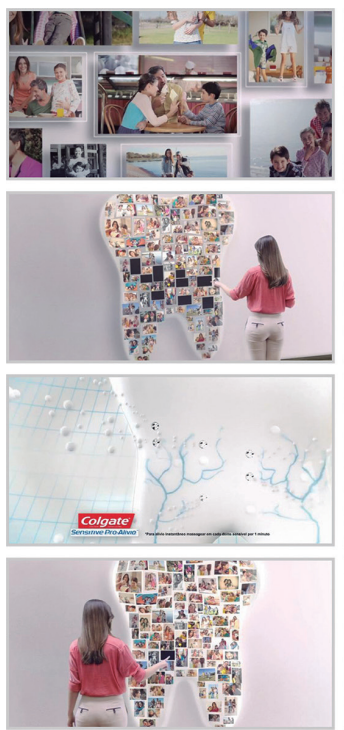

Fonte: Acervo da pesquisa.
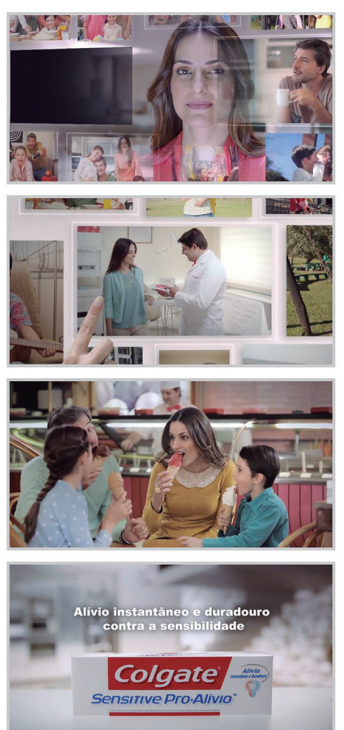
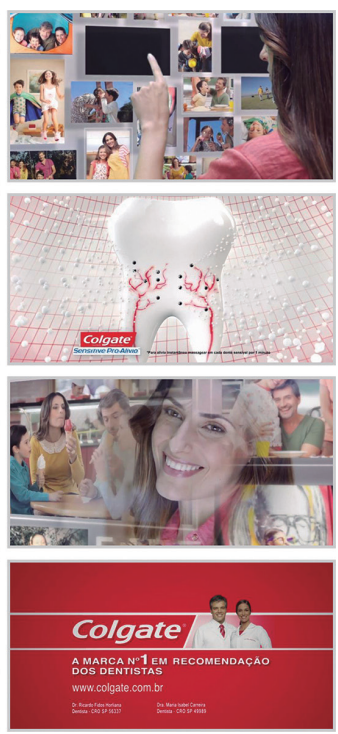
A presença do dentista é o que muda todo o rumo da narrativa. O que vem a seguir no anúncio marca a resolução da narrativa e reforça o reconhecimento de que um dentista pode indicar um creme dental. Neste mesmo anúncio, vemos ao final uma nova validação pelo conhecimento científico, mas agora não mais por um especialista interpretado por um ator, mas dois dentistas identificados pelo seu número do Conselho Regional de Odontologia (CRO), enfatizando o produto como portador de uma qualidade certificada pela ciência.

\section{Celebridades como personagens}

Outras personagens que chamam a atenção nas narrativas publicitárias analisadas são as celebridades 9 . Apesar de não serem representantes do conhecimento científico, elas assumem um papel de recomendação e ratificação dos resultados que a ciência oferece. Sua função é agregar ao produto o reconhecimento que possuem, associando a eles beleza, reputação e estilo de vida como benefícios científicos. Ou seja, idealizações que permeiam os produtos anunciados a partir do conhecimento científico.

Como personalidades públicas e pessoas que trabalham com a própria imagem, tanto no sentido da beleza quanto da reputação, as celebridades contribuem para a narrativa publicitária por associarem seus atributos pessoais aos resultados prometidos pelos produtos e atuam na identificação com o público. O que percebemos é que, em anúncios que utilizam a ciência e têm celebridades como personagens, geralmente, o conhecimento científico é uma solução para a vida delas. Identificamos a presença delas nas categorias de alimentos, bebidas, cosméticos, higiene doméstica, higiene pessoal e outros produtos farmacêuticos.

A celebridade é acionada de diferentes maneiras: ela tanto pode assumir a centralidade da argumentação com a sua própria personalidade; como pode interpretar uma outra personagem, porém, em ambos os casos, certificam o produto. Há anúncios em que a celebridade é

9 Entendemos o conceito de celebridade como "uma pessoa famosa e singular, reconhecida por um público e cuja fama pode variar conforme os 'sentimentos humanos', ou seja, segundo as impressões do público que a reconhece” (SIMÕES, 2013, p. 106). 
17683

apresentada de maneira ilustrativa, com um papel secundário, mas, ainda assim, pode chamar a atenção e contribuir com a abordagem do anúncio.

A presença da atriz Dira Paes como mediadora do desafio proposto pela Activia é uma importante ferramenta de contextualização do problema que as demais personagens enfrentam. Em uma conversa de amigas, ela se insere como quem sabe a solução e, ao final, depois da demonstração feita por meio de animação, consome e certifica o iogurte (Figura 8).

Figura 8 - Activia, "Dica de amiga vale ouro" (30")
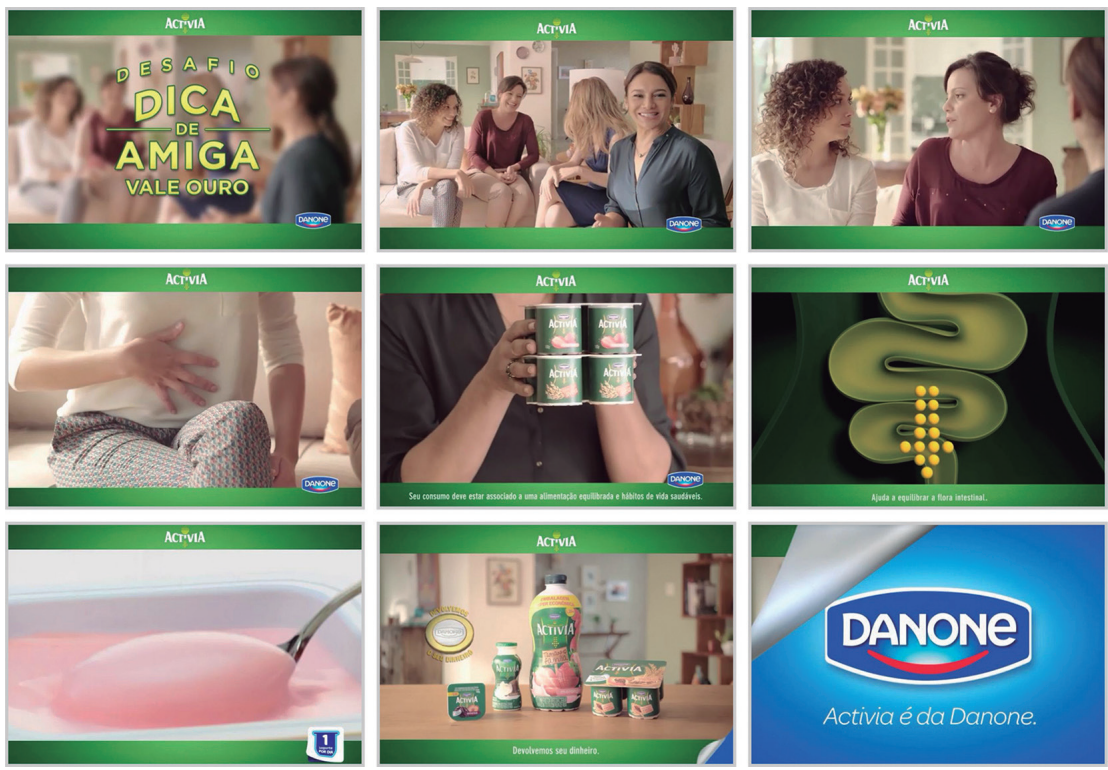

Fonte: Acervo da pesquisa.

O ambiente no qual o anúncio ocorre nos permite associar que aquele é o momento de saber um pouco mais sobre a vida das três personagens, como em uma entrevista televisiva. Como celebridade e mediadora, Dira assume a condução dos argumentos anunciados, tomando a posição de porta-voz da marca e dando sugestões. Assim, reconhecemos seu 
status diferenciado que dá a ela "permissão" de qualificar aos produtos. Dira, como outras celebridades, pode ser a personificação de estilos que idealizamos em saúde, beleza e outros nos quais a ciência pode nos ajudar a alcançar.

\section{Não especialistas como personagens}

Por último, mas não menos importantes, outras personagens presentes nas narrativas publicitárias que utilizam a ciência são os representantes do senso comum, os não especialistas. Eles não possuem a notoriedade das celebridades, mas são reconhecidos por vivenciarem o nosso dia a dia. Fictícios ou factuais, a essas personagens cabe apresentar o problema e/ou a sua solução a partir da experiência vivida. Ou seja, apesar de não deterem o conhecimento científico, eles validam os resultados. O conhecimento que possuem a partir do cotidiano consolida estratégias que reforçam não só os produtos anunciados, mas a própria ciência como solução para os problemas enfrentados diariamente.

Essa estratégia embasa e ratifica a satisfação com os resultados dos produtos desenvolvidos pelo conhecimento científico. A partir dos não especialistas, também reconhecemos nossas necessidades e desejos. Mais do que dividir o que aprenderam, eles nos representam. São pais, mães, jovens, idosos, mulheres e homens que estão nos anúncios para apresentar o que somos e o que idealizamos. Portanto, são importantes para que vejamos a ciência em ação, mas também para nos ensinar como podemos alcançar o que é mostrado pelo anúncio.

No anúncio sobre o João-de-Barro do Canal Futura vemos essas características no agricultor e no índio que compõem o conjunto de saberes sobre o pássaro. As demais personagens, a arquiteta e a bióloga, por exemplo, detêm informações científicas, já os não especialistas apresentam o reconhecimento pelo canto e a origem do pássaro pelas lendas, ou seja, pelo conhecimento tradicional (Figura 9). 
Figura 9 - Canal Futura, “João-de-Barro” (30”)
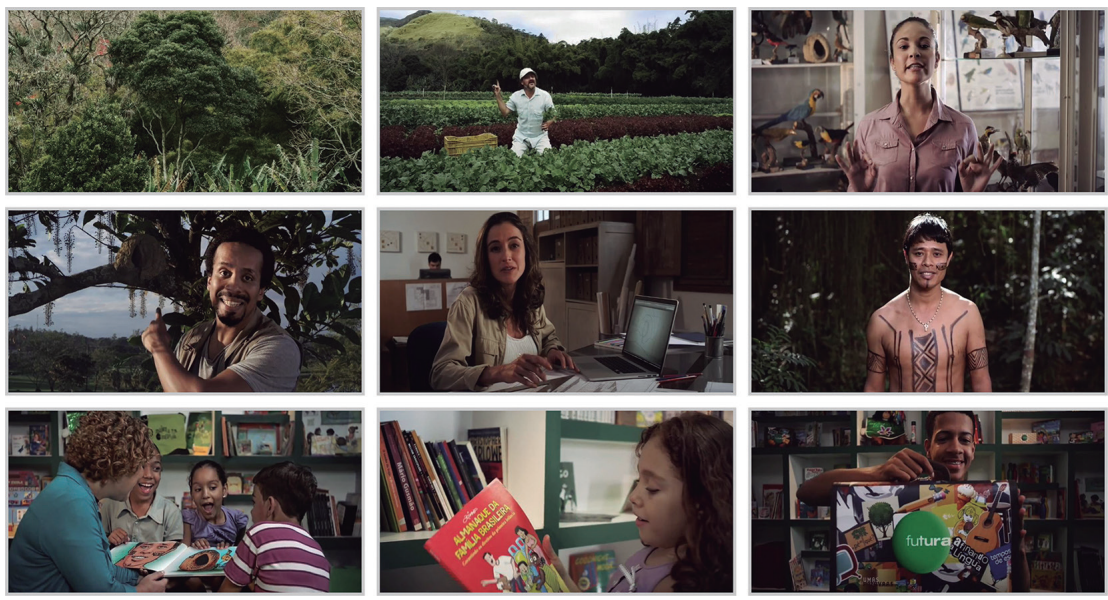

Fonte: Acervo da pesquisa.

O Canal Futura faz a apresentação do que será narrado no anúncio, marcando que é possível conhecer a natureza tendo contato com ela, por meio do reconhecimento feito pelo agricultor. As personagens falam o que conhecem sobre o pássaro a partir das suas especialidades (Arquitetura e Biologia), e o índio a partir da lenda popular que explica a existência do pássaro. Os depoimentos, baseados na observação e na tradição, reforçam o desfecho dado pela locução, apontando que o canal reúne as diversas formas de conhecer o mundo para compartilhar com todos que o assistem. Sabemos que nesse caso, a estratégia do anúncio não é de validação, mas apontamos como importante por conta da sua proposta educativa, que pode ser pensada como algo que permeia todos os anúncios com a presença das personagens não especialistas: eles são essenciais para que a ciência se consolide como um conhecimento que reflete no cotidiano.

\section{Considerações finais}

A ideia de ciência, nos anúncios analisados, é necessária para consolidar os diferenciais dos produtos. Porém, as formas como a publicidade 
consegue construir essa noção é que nos trouxe inquietações sobre a ciência nas narrativas publicitárias e os processos de comunicação que elas podem acionar. Assim, identificamos como cenários, personagens, sons, animações e informações em diversos suportes são recursos importantes para consolidar a referência à ciência como uma estratégia de construção da narrativa publicitária. É a partir daí que o conhecimento científico traz à publicidade as noções de experimentação, inovação, exclusividade, realidade, ficção, ludicidade, legitimação, entre outras.

Os anúncios orientam os seus recursos textuais, sonoros e imagéticos para a construção das nove estratégias que identificamos, e todos eles nos dizem algo sobre a ciência que reconhecemos em nosso dia a dia. O que se destaca é o conhecimento científico como fonte de soluções para nossas vidas - uma metanarrativa evidente. A lógica percebida em nossas análises, do conhecimento como solução, é sem dúvida algo que chama a atenção: a ciência é fundamental aos propósitos publicitários, mas é porque tem em si o reconhecimento de um saber para uma vida melhor.

Dessa maneira, os produtos podem ser publicizados a partir de um componente científico que, além de exclusivo, pode ser considerado como a inovação da década, testada e comprovada por especialistas, com a sua ação explicada passo a passo, sendo indicado por uma bela atriz e aprovado por pais como ideais para seus filhos. São possibilidade independentes, mas que se combinam para nos envolver nas narrativas publicitárias e enfatizar o papel da ciência em nosso cotidiano.

\section{Referências}

CASALLAS-TORRES, H. A. La ciencia en la televisión nacional: análisis de los comerciales de televisión. 2012. 175 f. Dissertação (Mestrado em Sociologia) - Facultad de Ciencias Humanas, Universidad Nacional de Colombia, Bogotá. 2012.

FIGUEIREDO, C. Redação publicitária: sedução pela palavra. São Paulo: Cengage Learning, 2014. 
FLAUSINO, M. C.; MOTTA, L. G. Break comercial: pequenas histórias do cotidiano. Narrativas publicitárias na cultura da mídia. Comunicação, Mídia e Consumo, São Paulo, v. 4, n. 11, p. 159-176, nov. 2007.

GOMES, N. D. Publicidade: comunicação persuasiva. Porto Alegre: Sulina, 2008.

KANTAR IBOPE MEDIA. Investimento publicitário: setores econômicos - janeiro a junho 2016. 2016. Disponível em: <http://www.kantaribopemedia.com/setores-economicos-janeiro-a-junho-2016/>. Acesso em: 6 jan. 2017.

MALCHER, M. A. et al. A ciência na TV aberta: uma exploração da programação de emissoras de Belém-PA. E-Compós, v. 20, n. 2, p. 1-20, maio/ago. 2017.

MOTTA, L. G. Análise crítica da narrativa. Brasília: Editora Universidade de Brasília, 2013.

PIEDRAS, E. R. Fluxo publicitário: anúncios, produtores e receptores. Porto Alegre: Sulina, 2009.

PITRELLI, N.; MANZOLI, F.; MONTOLLI, B. Science in advertising: uses and consumptions in the Italian press. Public Understanding of Science, v. 15, n. 2, p. 207-220, abr. 2006.

ROCHA, E. Representações do consumo: estudos sobre a narrativa publicitária. Rio de Janeiro: Ed. PUC-Rio/Mauad, 2006.

SIBILIA, P.; JORGE, M. F. O que é ser saudável? Entre publicidades moderna e contemporâneas. Galáxia, São Paulo, n. 33, p. 32-48, 2016.

SIMÕES, P. G. Celebridades na sociedade midiatizada: em busca de uma abordagem relacional. Revista ECO-Pós, Rio de Janeiro, v. 16, n. 1, p. 104-119, jan./abr. 2013.

TOALDO, M. M. Cenário publicitário brasileiro: anúncios e moralidade contemporânea. Porto Alegre: Sulina, 2005.

TRINDADE, E. A linguagem padrão e regional da publicidade: uma comparação entre os processos de significação em alguns comerciais recifenses e paulistanos nos anos 90. 1999. 257 f. Dissertação (Mestrado em Ciências da Comunicação) - Escola de Comunicações e Artes, Universidade de São Paulo, São Paulo. 1999.

TRINDADE, E. Propaganda, identidade e discurso: brasilidades midiáticas. Porto Alegre: Sulina, 2012.

\section{Sobre os autores}

Maria Ataide Malcher - Doutora em Ciências da Comunicação pela Universidade de São Paulo. Professora do Programa de Pós-Graduação Comunicação, Cultura e Amazônia da Universidade Federal do Pará e do Programa de 
Pós-Graduação em Divulgação da Ciência, Tecnologia e Saúde da Fundação Oswaldo Cruz.

Weverton Raiol - Mestre em Ciências da Comunicação pela Universidade Federal do Pará. Pesquisador do Laboratório de Pesquisa e Experimentação em Multimídia do Núcleo de Inovação e Tecnologias Aplicadas a Ensino e Extensão da Universidade Federal do Pará.

Data de submisão: 16/10/2017

Data de aceite: 21/02/2018 